\title{
In Vitro Cytotoxicity of Zinc Oxide Nanoparticles in Cultured Statens Seruminstitut Rabbit Cornea Cells
}

\author{
Handule Lee and Kwangsik Park \\ College of Pharmacy, Dongduk Women's University, Seoul, Korea
}

\begin{abstract}
The possibility of eye exposure for workers participating in manufacturing of nanoparticles or consumers using products containing nanoparticles has been reported, but toxicity studies on the eye are scarce. In this study, cytotoxicity of five nanoparticles including silver, ceria, silica, titanium and zinc were tested using Statens Seruminstitut Rabbit Cornea (SIRC) cells. When cells were treated with nanoparticles with concentrations of $1-100 \mu \mathrm{g} / \mathrm{mL}$ for $24 \mathrm{hr}$, zinc oxide nanoparticles showed higher toxicity to cornea cells. $\mathrm{LC}_{50}$ of zinc oxide nanoparticles was less than $25 \mu \mathrm{g} / \mathrm{mL}$ but those of other nanoparticles could not be calculated in this test, which means more than $100 \mu \mathrm{g} / \mathrm{mL}$. Generation of reactive oxygen species was observed, and expression of apoptosis related biomarkers including Bax and Bcl-2 were changed after treatment of zinc oxide nanoparticles, while no other significant toxicity-related changes were observed in cornea cells treated with $\mathrm{Ag}, \mathrm{CeO}_{2}, \mathrm{SiO}_{2}$ and $\mathrm{TiO}_{2}$ nanoparticles.
\end{abstract}

Key words: Zinc oxide nanoparticles, Cornea cells, Reactive oxygen species, Apoptosis

\section{INTRODUCTION}

As many different types of nanoparticles (NPs) are applied to consumer products, studies on risk for NPs have also rapidly increased $(1,2)$. It is now generally accepted that risk of NPs to environments and humans is the driving factor in limiting their use. In addition, new experimental models for estimating toxicity in vitro and in vivo are developing to collect more information about risk $(3,4)$. When NPs enter the body through inhalation, ingestion or skin contact, they are delivered to target organs including lung, liver, kidney or brain, and interact with cellular molecules to exert undesirable effects. Distribution of NPs to target organs is dependent on physicochemical characteristics including size, electrical charge, shape, and composition of the NP core and shell, as well as exposure routes. It is the reason why toxic responses of

Correspondence to: Kwangsik Park, College of Pharmacy, Dongduk Women's University, 60, Hwarang-ro 13-gil, Seongbuk-gu, Seoul 02748, Korea

E-mail: kspark@dongduk.ac.kr

This is an Open-Access article distributed under the terms of the Creative Commons Attribution Non-Commercial License (http:// creativecommons.org/licenses/by-nc/3.0) which permits unrestricted non-commercial use, distribution, and reproduction in any medium, provided the original work is properly cited.
NPs on living organisms are so diverse, even though NPs are produced from the same materials, e.g., silver or zinc $(5,6)$.

Recently, possible eye exposure of NPs from consumer products or industrial workplaces are reported (7). Eyes are directly exposed to the atmosphere, and direct contact between eyes and nanoparticles in the environment or workplaces can potentially lead to ocular damage. However, studies on potential adverse effects of industrial manufactured NPs to eyes are limited. Most studies are usually focused on the adverse effects of NPs for drug delivery, which are made from biocompatible materials $(7,8)$. Furthermore, data on eyes' toxicity caused by industrial NPs are inconsistent in many cases, depending on types of particles or exposure conditions. Nanoceria did not cause damage to the retinal structure and function at 30 day post injection, at doses ranging from 17.2-1,720 ng per eye. No cellular infiltration, and no increases in inflammatory responses were found in eyes (9). No significant decrease of cellular viability was observed, up to a concentration of $100 \mu \mathrm{g} / \mathrm{mL}$ for three different size silica nanoparticles (10). When in vitro culture model of mouse retina was treated with silver nanoparticles (AgNPs) and gold nanoparticles (AuNPs), significantly higher numbers of apoptotic cells, as well as an increased number of oxidative stressed cells were observed. Results suggested that low concentration 
of AgNPs and AuNPs have adverse effects on the retina (11). When C57BL/6 mice were intravenously injected with $20 \mathrm{~nm}$ AuNPs, particles were found in the retina but cells containing AuNPs did not show structural abnormality, and increase of cell death compared to the cells without AuNPs (12). In a test of acute eye irritation using rabbits, no significant clinical signs or mortality, and no acute irritation of corrosion reaction for the eye were observed (13). In the case of graphene oxide NPs, reduced type and oxidized type showed different effects on eye toxicity, when mice were exposed to $10 \mu \mathrm{L}$ of the NPs in conjunctival sacs with concentrations of 25,50 , and 100 $\mu \mathrm{g} / \mathrm{mL}$, once per day for a total of 7 days. Oxidized type caused obvious intraocular inflammation, incrassated corneal stroma layer, cell apoptosis in the cornea, iris neovascularization and significant cytotoxicity of corneal epithelial cells, while reduced type caused no significant ocular toxicity (14). Regarding zinc oxide nanoparticles (ZnONPs), they were reported to induce rat retina ganglion cell damage, through bcl-2, caspase-9 and caspase-12 pathways $(15,16)$. In this study, we tested cytotoxicity of metal based nanoparticles including AgNPs, titanium oxide nanoparticles (TiONPs), cerium oxide nanoparticles (CeONPs), silica oxide nanoparticles (SiONPs) and ZnONPs using cultured using Statens Seruminstitut Rabbit Cornea (SIRC) cells. SIRC cells are used on short time exposure (STE) test method for eye irritation test based on OECD Test guidline 491 . This study can provide information on eye toxicity caused by nanoparticles exposed to the human body, through consumer products or working in industrial environments.

\section{MATERIALS AND METHODS}

Nanoparticles. AgNPs were supplied by Fraunhofer, and CeONPs, SiONPs, TiONPs and ZnONPs, were supplied by JRC-IHCP. Types, suppliers and specified particle sizes are shown in Table 1. AgNPs were provided as viscous liquid preparation in tween20/PEG, and solid content of AgNPs preparation is 10.16 weight $\%$. AgNPs has tendency to sediment slowly. So, it was weighed after vigorous shaking. CeONPs, ZnONPs, TiONPs and SiONPs were provided as powder form, in light-protection vials. All nanomaterials were kept at room temperature in a humidity controlled cabinet.
Sonication and measurement of particles size. VibraCell ${ }^{\circledR}$ (Model VC 505, Sonics \& Materials, CT, USA) and $13 \mathrm{~mm}$ Probe (Model CV334, Sonics \& Materials, CT, USA) were used for sonication of NPs. NPs were prepared to concentration of $2.56 \mathrm{mg} / \mathrm{mL}$ in $0.05 \% \mathrm{BSA}$, with ethanol pre-wetting. A total of $6 \mathrm{~mL}$ of suspension was added into a $20 \mathrm{~mL}$ glass vial, and sonicated at $25 \%$ amplitude $(500 \mathrm{~W}, 20 \mathrm{kHz})$ for $8 \mathrm{~min}$. Suspension was cooled in an ice-water during the sonication procedure and then was warmed in $25^{\circ} \mathrm{C}$ water bath for $5 \mathrm{~min}$. NPs suspension were prepared to $100 \mu \mathrm{g} / \mathrm{mL}$ concentration in Dulbecco's Modified Eagle's Medium (DMEM), containing 10\% fetal bovine serum (FBS) and dynamic light scattering (DLS) analysis was performed, at $25^{\circ} \mathrm{C}$ using particle size analyzer ELS-Z (Otsuka Electronics, Osaka, Japan) at $24 \mathrm{hr}$ after suspending to medium.

Cell culture. Statens Seruminstitut Rabbit Cornea (SIRC) cells are cell lines, derived from rabbit corneal and supplied from ATCC. SIRC cells were cultured in Dulbecco's Modified Eagle Medium (DMEM) containing 10\% heatinactivated fetal bovine serum (FBS), $1 \%$ penicillin and streptomycin $(1,000 \mathrm{U} / \mathrm{mL}$ penicillin and $100 \mu \mathrm{g} / \mathrm{mL}$ streptomycin) at $37^{\circ} \mathrm{C}$ with $5 \% \mathrm{CO}_{2}$ condition. Cells were seeded by the number of $6 \times 10^{5}$ cell $/ \mathrm{mL}$ in each well of 96-well plate, and pre-incubated for $24 \mathrm{hr}$ for cytotoxicity assay.

Cytotoxicity assay. Cytotoxicity was measured by the MTT (3-(4,5-dimethylthiazol-2-yl)-2,5-diphenyltetrazolium bromide) assay. Cells were seeded on 96-well tissue culture plates, with $6 \times 10^{4}$ cells in $100 \mu \mathrm{L}$ media per well. After $24 \mathrm{hr}$ stabilization of cells, they were treated with 1 , $10,12.5,25,50$ and $100 \mu \mathrm{g} / \mathrm{mL}$ concentrations of NPs for $24 \mathrm{hr}$, respectively. Control cells were treated with the vehicle only. At the end of exposure, $100 \mu \mathrm{L}$ of MTT solution $(5 \mathrm{mg} / \mathrm{mL})$ was added, and cells were incubated for $2 \mathrm{hr}$ at $37^{\circ} \mathrm{C}$. Cells were treated with $100 \mu \mathrm{L}$ of DMSO, and absorbance was quantified in $570 \mathrm{~nm}$ using the microplate spectrophotometer system (VersaMax, Molecular Devices, Sunnyvale, CA, USA).

ROS generation. Cells grown to confluence in 12 well-plate at $24 \mathrm{hr}$ after seeding $\left(1 \times 10^{3}\right.$ cells in each well $)$ were treated with $1,10,25,50$ and $100 \mu \mathrm{g} / \mathrm{mL}$ of ZnONPs

Table 1. Specifications of nanoparticles used in this study

\begin{tabular}{lllccc}
\hline \hline Type of NM & Supplier name & Material code & Size (nm, as prepared) & Color & State \\
\hline TiONPs & JRC-IHCP & NM101 & 6 & White & Powder \\
ZnONPs & JRC-IHCP & NM111 & 141 & White & Powder \\
SiONPs & JRC-IHCP & NM200 & 18.3 & White & Powder \\
CeONPs & JRC-IHCP & NM212 & 33 & Cream & Powder \\
AgNPs & Fraunhofer & NM300K & 16.7 & Blackish brown & Liquid \\
\hline
\end{tabular}


Table 2. Primer sequences of genes used in this study

\begin{tabular}{|c|c|c|}
\hline Gene name & GB No. & Primer sequences \\
\hline \multirow[t]{2}{*}{ GAPDH } & NM-001082253.1 & F: 5'-AGACGGCGTCTGTAGAAGCT-3' \\
\hline & & R: 5'-GGGCCAAGTCCCACTATTGC-3' \\
\hline \multirow[t]{2}{*}{ Bcl-2 } & XM_008261439.2 & F: 5'-AGACGGCGTCTGTAGAAGCT-3' \\
\hline & & R: 5'-GGGCCAAGTCCCACTATTGC-3' \\
\hline \multirow[t]{2}{*}{ Bax } & XM_008252361.2 & F: 5'-CATTGGCGACGAACTGGACA-3' \\
\hline & & R: 5'-GTGCACAGGGCCTTGAGTAC-3' \\
\hline \multirow[t]{2}{*}{ Heme oxygenase-1 } & XM_002711415.3 & F: 5'-CAGCTTGCCCCAGGATTTGT-3' \\
\hline & & R: 5'-TACAGGGAGGCCATCACCAG-3' \\
\hline \multirow[t]{2}{*}{ Tumor necrosis factor (TNF-a) } & NM_001082263.1 & F: 5'-GGAGCTGCCTTGGTTCTCAC-3' \\
\hline & & R: 5'-ATGTAGCGACGGGTCAGTCA-3' \\
\hline \multirow[t]{2}{*}{ Matrix metallopeptidase 1 (MMP-1) } & NM_001171139.2 & F: 5'-GTGTGGAGTGCCTGATGTGG-3' \\
\hline & & R: 5'-TGGCATTGTCCACATCTGCC-3' \\
\hline
\end{tabular}

for the designated time $(0,3,6,9,12$, and $24 \mathrm{hr})$, then incubated with $40 \mu \mathrm{M}$ of 2,7-dichlorofluorescin diacetate ( $\mathrm{H}_{2} \mathrm{DCFDA}$ ) (Invitrogen, CA, USA) for $1 \mathrm{hr}$. At the end of $\mathrm{H}_{2}$ DCFDA incubation, cells were washed with phosphate buffered saline (PBS), and were visualized with a fluorescent microscope (Nikon, Tokyo, Japan). Effects of AgNPs, CeONPs, TiONPs and SiONPs on ROS generation were also tested compared to those of ZnONPs.

mRNA expression. Cells were incubated with $\mathrm{ZnONPs}$ for designated times $(3,6,9,12$ and $24 \mathrm{hr})$ and concentrations $(1,25,100 \mathrm{ppm})$. For preparation of total RNA, RiboEx $^{\text {TM }}$ (GeneAll, Seoul, Korea) was used, according to manufacturer's instruction. Reverse transcription (RT)PCR was performed with $1 \mu \mathrm{g}$ of total RNA, $1 \mu \mathrm{L}$ of 100 pmol oligo dT primer and reaction mixture, in total $20 \mu \mathrm{L}$ volume at $42^{\circ} \mathrm{C}$ for $60 \mathrm{~min}$. Then PCR was performed for $25-30$ cycles at $95^{\circ} \mathrm{C}$ for $20 \mathrm{sec}, 55^{\circ} \mathrm{C}$ for $20 \mathrm{sec}$, and $72^{\circ} \mathrm{C}$ for $30 \mathrm{sec}$. Amplified cDNA products using proper oligoprimers were separated on $1 \%$ agarose gel by electrophoresis. Primer sequences of amplified genes are shown in Table 2. GAPDH were also amplified and shown to be a loading control.

\section{RESULTS}

Size distribution of nanoparticles in culture media. Size distribution of tested nanoparticles including AgNPs, CeONPs, SiONPs, TiONPs and ZnONPs were shown in Fig. 1, 2. After sonication described in Methods, stock solution of NPs $(2.56 \mathrm{mg} / \mathrm{mL}$ in $0.05 \% \mathrm{BSA})$ was diluted to $100 \mu \mathrm{g} / \mathrm{mL}$ DMEM containing $10 \% \mathrm{FBS}$, and diluted NPs were standing for $24 \mathrm{hr}$ at room temperature and applied to DLS measurement. As shown in Fig. 1, NPs seemed to be aggregated or agglomerated in the media, and particles' size significantly increased compared to those of original specifications (Table 1). AgNPs increased 16.7$129.7 \mathrm{~nm}$ and $\mathrm{ZnONPs}$ increased 141-404 nm. Most increase was shown in TiONPs at $6-780 \mathrm{~nm}$. The representative

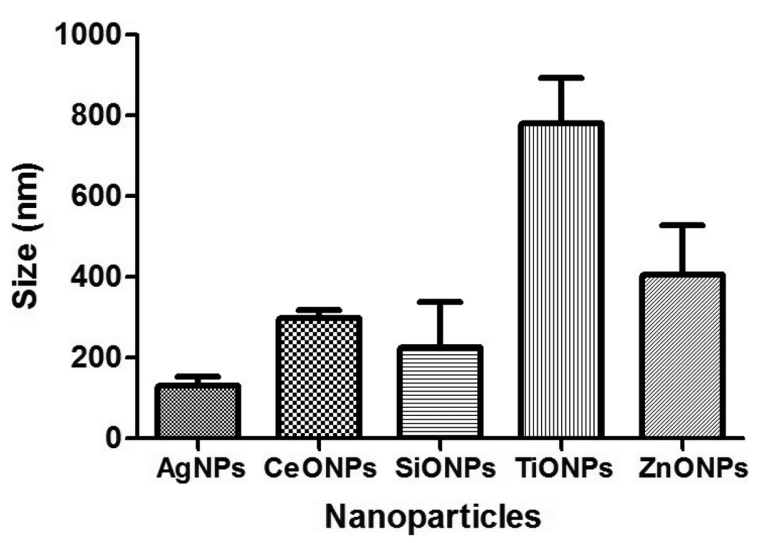

Fig. 1. Size of NPs at $24 \mathrm{hr}$ after suspending in DMEM media containing $10 \%$ FBS. Nanoparticles were prepared to concentration of $2.56 \mathrm{mg} / \mathrm{mL}$ in $0.05 \% \mathrm{BSA}$ with ethanol pre-wetting. A total $6 \mathrm{~mL}$ of suspension was added into $20 \mathrm{~mL}$ glass vial and sonicated at $25 \%$ amplitude $(500 \mathrm{~W}, 20 \mathrm{kHz}$ ) for $8 \mathrm{~min}$. NPs suspension were prepared to $100 \mu \mathrm{g} / \mathrm{mL}$ concentration in Dulbecco's Modified Eagle's Medium (DMEM) containing 10\% fetal bovine serum (FBS) and dynamic light scattering analysis was performed using particle size analyzer ELS-Z.

diagram for size distribution of NPs in DMEM containing $10 \%$ FBS at $24 \mathrm{hr}$ after preparation was shown in Fig. 2.

Cytotoxicity of ZnONPs. SIRC cells were incubated with different concentrations $(1,10,12.5,25,50$, and 100 $\mu \mathrm{g} / \mathrm{mL}$ ) of test NPs for $24 \mathrm{hr}$, and viability was determined. As shown in Fig. 3, cell viability decreased only in ZnONPs-treated groups in the test concentrations. The other NPs did not show cytotoxicity in tested concentration, during designated incubation time. AgNPs seemed to induce cytotoxicity in highest concentration of $100 \mathrm{ppm}$, but toxicity was weak, compared to those of ZnONPs. Cell viability decreased to approximately $20 \%$ in 25 ppm of ZnONPs, while cell viabilities were not affected by treatment of other NPs. Short-term effect of ZnONPs were tested within $24 \mathrm{hr}$ of exposure time. Cell viability was 

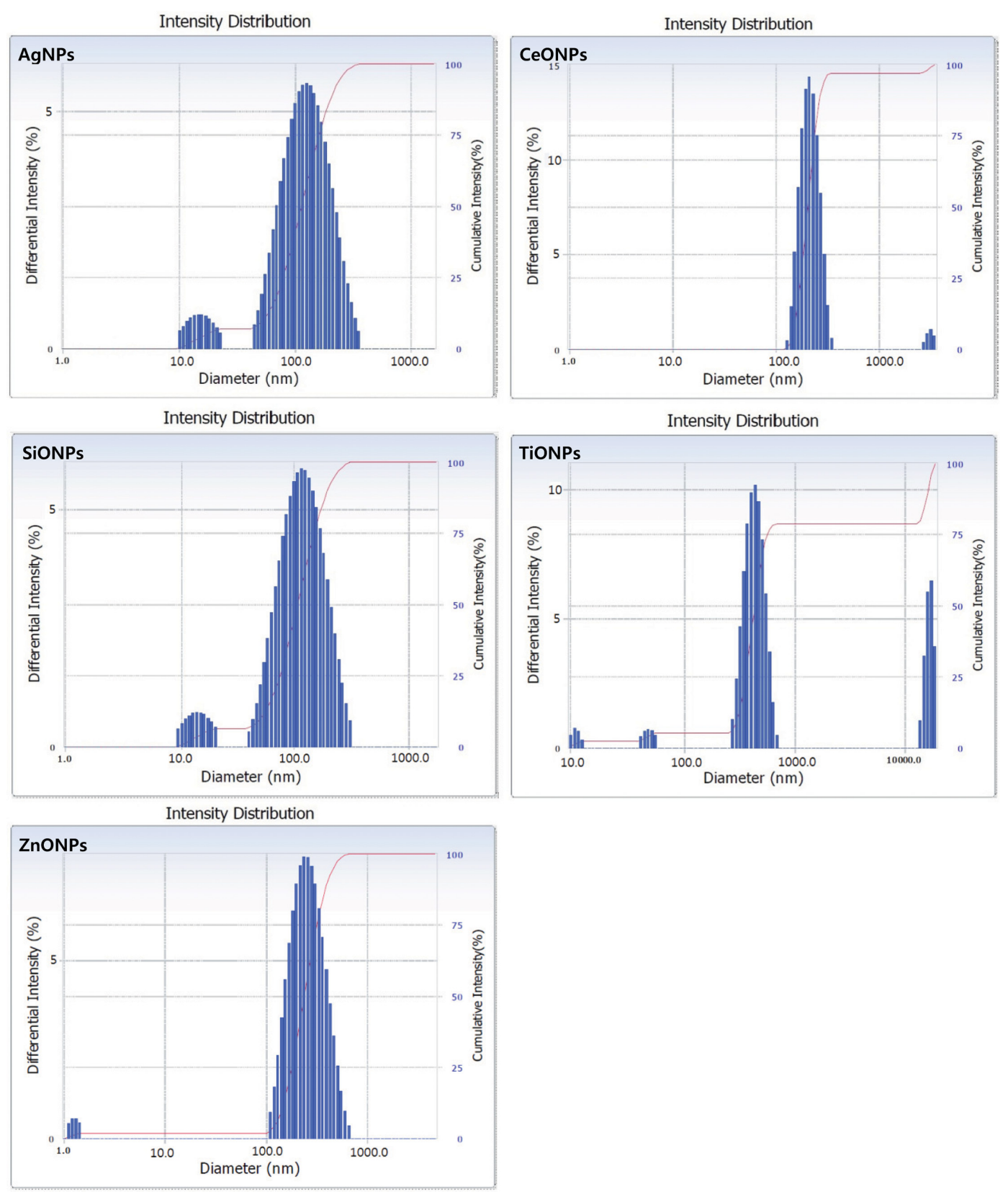

Fig. 2. Representative diagram of size distribution of tested nanoparticles. Nanoparticles suspension were prepared to $100 \mu \mathrm{g} / \mathrm{mL}$ concentration in Dulbecco's Modified Eagle's Medium (DMEM) containing 10\% fetal bovine serum (FBS) and dynamic light scattering analysis was performed using particle size analyzer ELS-Z. Sizes of NPs in DMEM increased due to aggregation and/or agglomeration.

measured at 3, 6, 9, 12 and $24 \mathrm{hr}$ after treatment with different concentration $(1,10,12.5,25,50$, and $100 \mu \mathrm{g} / \mathrm{mL})$. Time- and concentration-dependent cytotoxicity of ZnONPs were shown in Fig. 4.

ROS generation. Images of ROS production in cultured SIRC cells treated with NPs at $25 \mu \mathrm{g} / \mathrm{mL}$ for $24 \mathrm{hr}$ were obtained, using fluorescent microscope by $\mathrm{H}_{2}$ DCFDA method. Significant evidence of ROS generation by treat- ment of AgNPs, CeONPs, SiONPs, and TiONPs was not detected, as in the non-treated control group, but fluorescent cells were shown only in ZnONPs-treated cells (images not shown). Most of the incubated cells treated with ZnONPs were detached from wells, from induced cytotoxicity, while other groups of cells were confluent and viable (images not shown). Time course of ROS generation in ZnONPs treated cells was shown in Fig. 5. When cells were exposed to $25 \mu \mathrm{g} / \mathrm{mL}$ ZnONPs, fluores- 


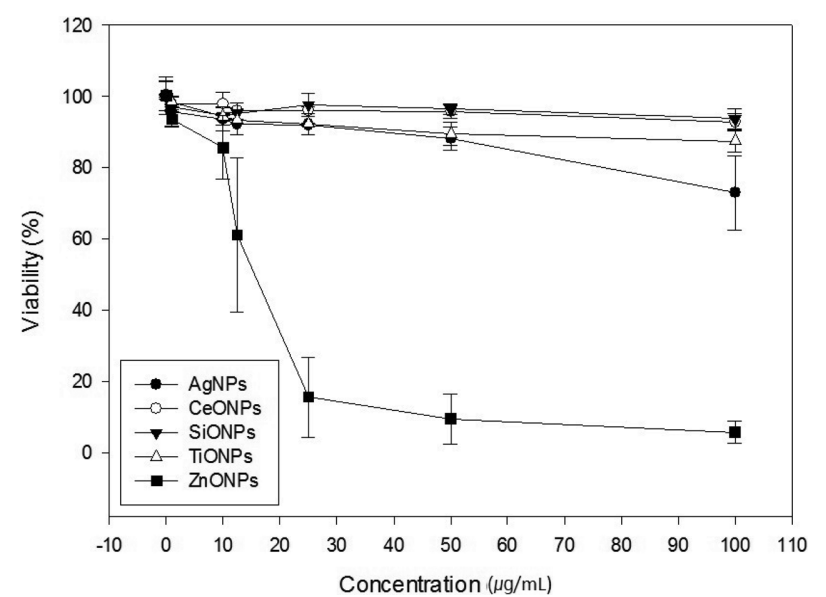

Fig. 3. Effects of nanoparticles on the viability of cultured SIRC cells. Cell viability was assessed by MTT assays, and results are presented as percentage of control group viability. Cells were treated with indicated concentrations $(1,10,12.5,25,50,100$ $\mu \mathrm{g} / \mathrm{mL}$ ) for $24 \mathrm{hr}$. Results represent the means of three separate experiments, and error bars represent the standard error of the mean.

cent images were evident, compared to the non-treated control group at $9 \mathrm{hr}$ of exposure and were intensified by increase of exposure time. Concentration dependency was also shown in $9 \mathrm{hr}$ of exposure (images were not shown).

Gene expression related with oxidative stress and apoptosis. To investigate expression level of mRNA related to responses of oxidative stress and cell death in

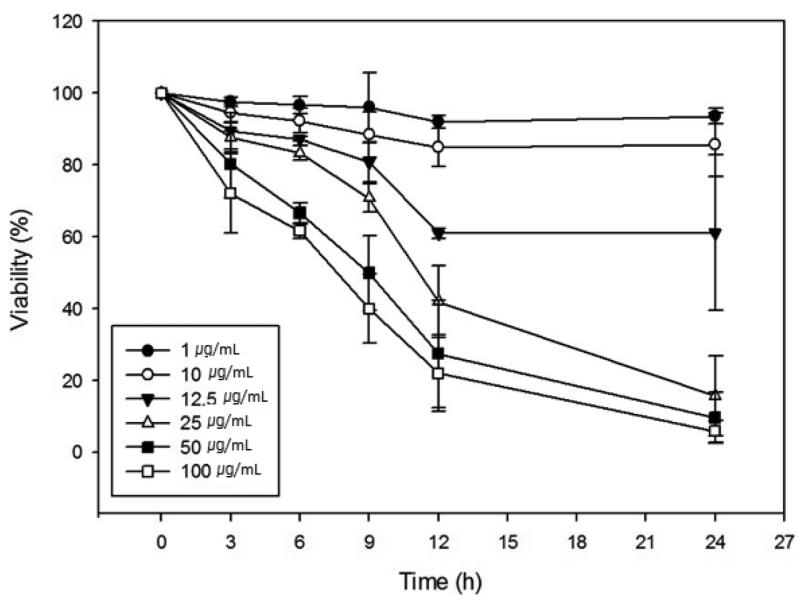

Fig. 4. Effects of zinc oxide nanoparticles on the viability of cultured SIRC cells. Cell viability was assessed by MTT assays, and results are presented as percentage of the control group viability. Cells were treated with indicated concentrations (1, $10,12.5,25,50,100 \mu \mathrm{g} / \mathrm{mL}$ ) and times (3, 6, 9, 12, $24 \mathrm{hr}$ ). Results represent the means of three separate experiments, and error bars represent standard error of the mean.

SIRC cells, RT-PCR was performed. As shown in Fig. 6, heme oxygenase was induced by ZnONPs. It was timedependent (Fig. 6A) and concentration dependent (Fig. $6 \mathrm{~B})$. Bax, which is one of the apoptosis promoting genes, was induced as the same expression pattern of heme oxygenase, while Bcl-2, an anti-apoptosis gene decreased. Inflammation-related genes such as TNF-a was also induced by ZnNPs, but not in the case of MMP-1. Other NPs,
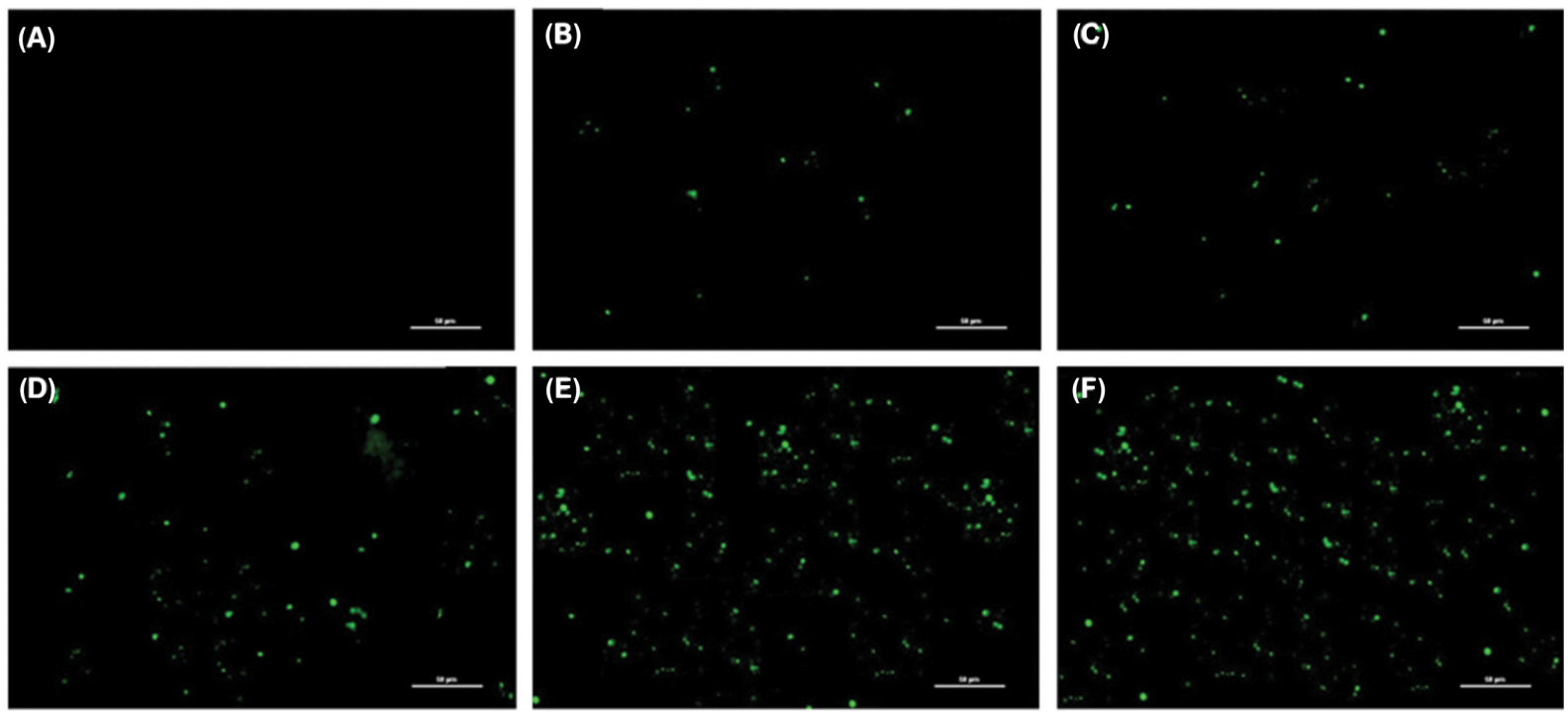

Fig. 5. Effects of zinc oxide nanoparticles on ROS induction in cultured SIRC cells. Cells were treated with $25 \mu \mathrm{g} / \mathrm{mL} \mathrm{ZnNPs}$ for 3,6 , $9,12,24 \mathrm{hr}$, respectively, and then DCFH-DA was added to cells. Cells were visualized with a fluorescent microscope $(\times 250)$ and representative images were shown. (A) Non-treated control group, (B) $3 \mathrm{hr}$ treatment, (C) $6 \mathrm{hr}$ treatment, (D) $9 \mathrm{hr}$ treatment, (E) $12 \mathrm{hr}$ treatment, (F) $24 \mathrm{hr}$ treatment. 


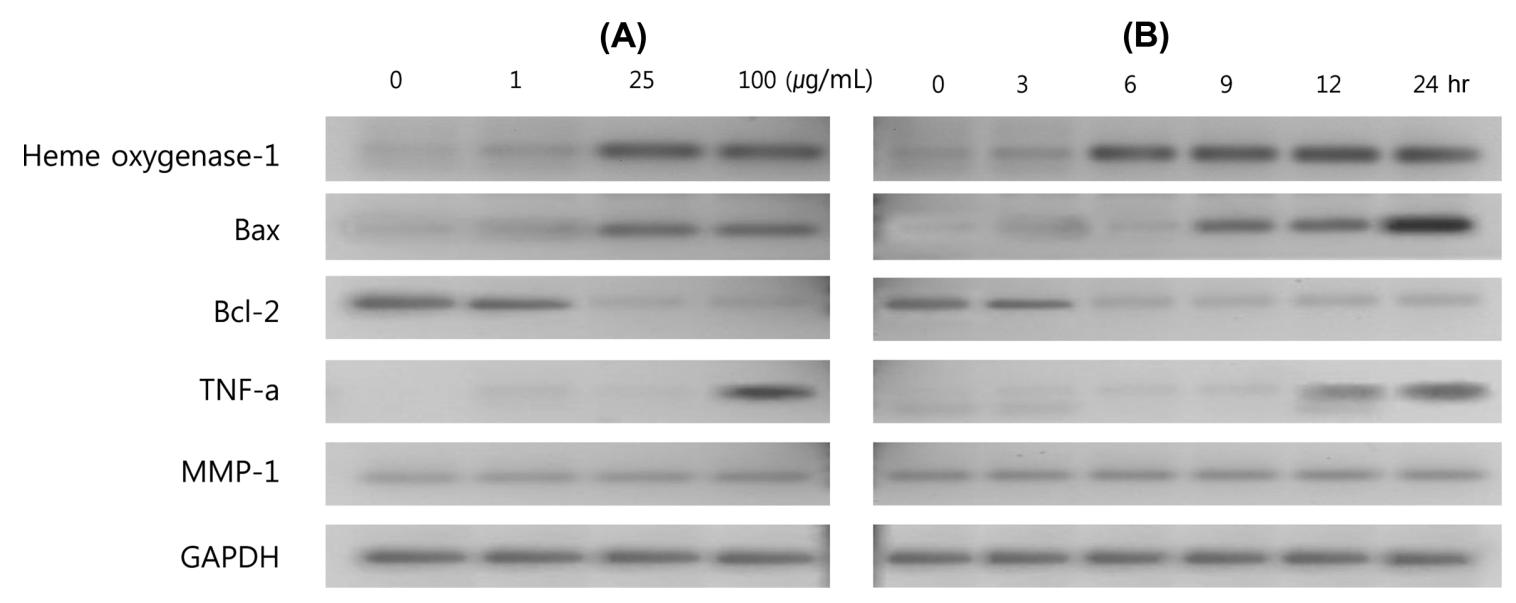

Fig. 6. Effect of ZnNPs on the induction of gene expression in cultured SIRC cells. Gene expression was analyzed for concentration-dependent effect (A) and time-course effect (B). Cells were treated with ZnNPs $(1,25,100 \mu \mathrm{g} / \mathrm{mL})$ for 3, 6, 9, 12, and 24 hr, respectively. mRNA transcription was determined by RT-PCR analysis using respective primers described in Table 2 . Results were confirmed by three separate experiments, and representative images are shown.

(A)

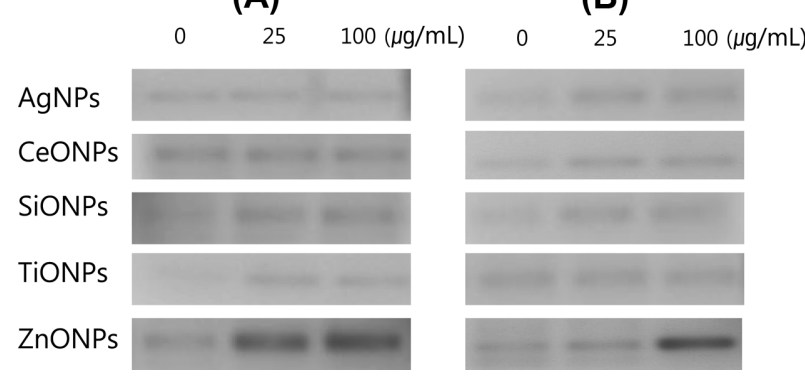

Fig. 7. Effect of nanoparticles on the gene expressions of heme oxygenase and Bax in cultured SIRC cells. Gene expressions of heme oxygenase (A) and Bax (B) were analyzed in SIRC cells treated with AgNPs, CeONPs, SiONPs, TiONPs, and ZnONPs. NPs were treated to cells with concentrations of 25 and $100 \mu \mathrm{g} / \mathrm{mL}$ for $24 \mathrm{hr}$, respectively. mRNA transcription was determined by RT-PCR analysis using respective primers described in Table 2. Results were confirmed by three separate experiments, and representative images are shown.

including AgNPs, CeONPs, TiONPs and SiONPs, did not show effect on expression of heme oxygenase, and Bax genes involved in oxidative stress or apoptosis (Fig. 7).

\section{DISCUSSION}

Toxicity studies of nanoparticles on eyes are few, while eyes may be the direct exposure target of particles. Recently, eye irritation testing of nanomaterials using the EpiOcu$\operatorname{lar}^{\mathrm{TM}}$ eye irritation test and bovine corneal opacity and permeability (BCOP) assay was performed (17). In the study, 20 nanosized and 3 non-nanosized materials were investigated, including metals $(\mathrm{Ag})$ and metal oxides $(\mathrm{ZnO}$, $\mathrm{TiO}_{2}, \mathrm{CeO}_{2}$ ), amorphous $\mathrm{SiO}_{2}$, and MWCNTs. According to results, none of the dry-powder nanomaterials elicited eye irritation in the EpiOcular ${ }^{\mathrm{TM}}$-EIT or the BCOP assay. By contrast, in the EpiOcular ${ }^{\mathrm{TM}}$-EIT, silver nanomaterial supplied as dispersion tested positive. $\mathrm{CdSe} / \mathrm{ZnS}$ core/shell quantum dots (QDs) capped with three different functional groups, were tested for risk assessment of eye exposure (18). An in vitro cytotoxicity test using bovine corneal stromal cells incubated individually with all three kinds of QDs, indicated that cell viability decreased significantly as QD concentration and incubating period increased.

In this study, SIRC cells were used for cytotoxicity testing of nanomaterials and toxicity was compared. As shown Fig. 3, ZnONPs are the only nanoparticles, to show significant toxicity in cultured SIRC cells in the tested concentrations. Compared to other nanoparticles, ZnONPs showed serious damage to cornea cells. The reason or mechanism to show the difference in ZnONPs-treated cells, are not elucidated in this study. By contrast to other nanoparticles, relatively much more information on eye toxicity caused by zinc nanoparticles, can be obtained from open publications. In cultured retinal ganglion cells treated with ZnONPs, reactive oxygen species (ROS) were produced, and mitochondrial membrane potential was disturbed. It was known that ZnONPs induced rat retinal ganglion cell damage through bcl-2, caspase- 9 and caspase-12 pathway $(15,16)$. ZnONPs also induced cytotoxicity to murine photoreceptor cells. ZnONPs increased lactate dehydrogenase release in medium, aggravate ROS level within cells, collapse mitochondrial membrane potential, block delayed rectifier potassium current, and attenuate expressions of $\mathrm{Na}^{+} / \mathrm{K}^{+}$-ATPase at mRNA and protein levels and its activity $(19,20)$. ZnONPs also showed adverse effects on murine photoreceptor cells, via reducing TGF- $\beta$ and MMP-9 expression in vitro (21). Regarding selective toxicity of 
ZnONPs to SIRC cells, it seems that there are some different proteins or signals with roles in cytotoxic pathway in SIRC cells. ZnONPs did not show significant difference among other nanoparticles such as silver, titanium, silica and ceria in effects of cell viability, when they were added to cultured THP-1 cells or A549 cells $(22,23)$. Based on results of a previous cytotoxicity study and this study using SIRC cells, ZnONPs seems to show selective and more specific toxicity to SIRC compared to other metal nanoparticles. In retina, zinc has significant physiological roles, and inherited disorders of its metabolism, are associated with retinal dysfunction and significant visual loss (24). Zinc is required for anti-oxidant defense and the function of retinol dehydrogenase, the enzyme involved in retinol processing in the visual cycle. In addition, many proteins are dependent on zinc, so that deficit of zinc may cause serious diseases in humans. However, no retinal abnormalities have been described in patients with zinc overload (25). No other data on selective toxicity to eyes caused by zinc or zinc nanoparticles have been found.

ROS generation in cultured SIRC cells treated by ZnONPs were also observed in this study and results are confirmed by images of the fluorescent microscope (Fig. 5 ) and increased gene expression of heme oxygenase, one of known biomarkers of oxidative stress in cells (Fig. 6, 7). Induced patterns of ROS generation were very similar to those of cytotoxicity test, which shows time- and concentration-dependent responses. The reasons of toxicity difference observed between $\mathrm{ZnONPs}$ and other nanoparticles in this study are unknown. However, it seems that over load of $\mathrm{Zn}$ ion released from ZnONPs may disturb homeostasis of zinc metabolism, and may cause adverse effect of normal physiological roles driven by zinc to cell death. This is a reason why further study on eye toxicity of ZnONPs is needed. The same pattern of gene expression was also observed in Bax, a biomarker of cell apoptosis. Selective toxicity of ZnONPs to SIRC cells were unexpected, and we are trying to expand the study to other cells, including skin cells.

Higher cytotoxicity of ZnONPs than other NPs in this study, does not seem to be a result of size difference of NPs because other NPs such as AgNPs, CeONPs and SiONPs are smaller than ZnONPs (Fig. 1, 2). Although average mean size of NPs at $24 \mathrm{hr}$ are significantly increased from those described in specifications of the supplier (Fig. 1, Table 1), ZnONPs showed significant cytotoxicity to SIRC cells, compared to other NPs. It seems that chemical characteristics of metalloid particles are more critical, than size distribution of NPs. Rates of size increase after suspending in DMEM, are different among NPs, and they do not seem to affect cytotoxicity to SIRC cells.

In summary, ZnONPs showed higher cytotoxicity to cultured SIRC cells, compared to other nanoparticles such as AgNPs, CeONPs, SiONPs, and TiONPs, and this was supported by ROS generation and gene expression data. The mechanism was not elucidated in this study, and further study will be performed including accumulation of ZnONPs in SIRC cells.

\section{ACKNOWLEDGMENTS}

This study was supported by the Sabbatical Program of Dongduk Women's University.

\section{CONFLICT OF INTEREST}

We declare that we have no conflict of interest.

Received January 16, 2019; Revised April 23, 2019; Accepted June 3, 2019

\section{REFERENCES}

1. Warheit, D.B. (2018) Hazard and risk assessment strategies for nanoparticle exposures: how far have we come in the past 10 years? F1000Res., 7, 376.

2. Jeevanandan, J., Barhoum, A., Chan, Y.S., Dufresne, A. and Danquah, M.K. (2018) Review on nanoparticles and nanostructured materials: history, sources, toxicity and regulations. Beilstein. J. Nanotechnol., 9, 1050-1074.

3. Dwivedi, S., Saquib, Q., Ahmad, B., Ansari, S.M., Azam, A. and Musarrat, J. (2018) Toxicogenomics: A New Paradigm for Nanotoxicity Evaluation. Adv. Exp. Med. Biol., 1048, 143-161.

4. Kovalishyn, V., Abramenko, N., Kopernyk, I., Charochkina, L., Metelytsia, L., Tetko, I.V., Peijnenburg, W. and Kustov, L. (2018) Modelling the toxicity of a large set of metal and metal oxide nanoparticles using the OCHEM platform. Food Chem. Toxicol., 112, 507-517.

5. Choi, S.J. and Choy, J.H. (2014) Biokinetics of zinc oxide nanoparticles: toxicokinetics, biological fates, and protein interaction. Int. J.Nanomedicine, 2, 261-269.

6. Huang, Y.W., Cambre, M. and Lee, H.J. (2017) The toxicity of nanoparticles depends on multiple molecular and physicochemical mechanisms. Int. J. Mol. Sci., 18, 2702.

7. Mehra, N.K., Cai, D., Kuo, L., Hein, T. and Palakurthi, S. (2016) Safety and toxicity of nanomaterials for ocular drug delivery applications. Nanotoxicology, 10, 836-860.

8. Prow, T.W. (2010) Toxicity of nanomaterials to the eye. Wiley Interdiscip. Rev. Nanomed. Nanobiotechnol., 2, 317-333.

9. Cai, X., Seal, S. and McGinnis, J.F. (2016) Non-toxic retention of nanoceria in murine eyes. Mol. Vis., 22, 1176-1187.

10. Park, J.H., Jeong, H., Hong, J., Chang, M., Kim, M., Chuck, R.S., Lee, J.K. and Park, C.Y. (2016) The effect of silica nanoparticles on human corneal epithelial cells. Sci. Rep., 6 , 37762.

11. Erika, S., Patrik, B., Tommy, C., Hodan, A., Fredrik, J. and Ulrica, E.J. (2014) Silver and gold nanoparticles exposure to in vitro cultured retina - studies on nanoparticle internalization, apoptosis, oxidative stress, glial- and microglial activity. PLOS ONE, 9, e105359. 
12. Kim, J.H., Kim, J.H., Kim, K.W., Kim, M.H. and Yu, Y.S. (2009) Intravenously administered gold nanoparticles pass through the blood-retinal barrier depending on the particle size, and induce no retinal toxicity. Nanotechnology, 20, 505101.

13. Kim, J.S., Song, K.S., Sung, J.H., Ryu, H.R., Choi, B.G., Cho, H.S., Lee, J.K. and Yu, I.J. (2013) Genotoxicity, acute oral and dermal toxicity, eye and dermal irritation and corrosion and skin sensitisation evaluation of silver nanoparticles. Nanotoxicology, 7, 953-960.

14. An, W., Zhang, Y., Zhang, X., Li, K., Kang, Y., Akhtar, S., Sha, X. and Gao, L. (2018) Ocular toxicity of reduced graphene oxide or graphene oxide exposure in mouse eyes. Exp. Eye Res., 174, 59-69.

15. Guo, D., Bi, H., Wu, Q., Wang, D. and Cui, Y. (2013) Zinc oxide nanoparticles induce rat retinal ganglion cell damage through bcl-2, caspase-9 and caspase-12 pathways. J. Nanosci. Nanotechnol., 13, 3769-3777.

16. Guo, D., Bi, H., Liu, B., Wu, Q., Wang, D. and Cui, Y. (2013) Reactive oxygen species-induced cytotoxic effects of zinc oxidenanoparticles in rat retinal ganglion cells. Toxicol. In Vitro, 27, 731-738.

17. Kolle, S.N., Sauer, U.G., Moreno, M.C., Teubner, W., Wohlleben, W. and Landsiedel, R. (2016) Eye irritation testing of nanomaterials using the EpiOcular ${ }^{\mathrm{TM}}$ eye irritation test and the bovine corneal opacity and permeability assay. Part. Fibre Toxicol., 13, 18.

18. Kuo, T.R., Lee, C.F., Lin, S.J., Dong, C.Y., Chen, C.C. and
Tan, H.Y. (2011) Studies of intracorneal distribution and cytotoxicity of quantum dots: riskassessment of eye exposure. Chem. Res. Toxicol., 24, 253-261.

19. Chen, C., Bu, W., Ding, H., Li, Q., Wang, D., Bi, H. and Guo, D. (2017) Cytotoxic effect of zinc oxide nanoparticles on murine photoreceptor cellsvia potassium channel block and $\mathrm{Na}+/ \mathrm{K}+$-ATPase inhibition. Cell Prolif., 50, e12339.

20. Wang, L., Chen, C., Guo, L., Li, Q., Ding, H., Bi, H. and Guo, D. (2018) Zinc oxide nanoparticles induce murine photoreceptor cell death viamitochondria-related signaling pathway. Artif. Cells Nanomed. Biotechnol., 28, 1-12.

21. Guo, D.D., Li, Q.N., Li, C.M. and Bi, H.S. (2015) Zinc oxide nanoparticles inhibit murine photoreceptor-derived cell proliferation and migration via reducing TGF- $\beta$ and MMP-9 expression in vitro. Cell Prolif., 48, 198-208.

22. Lee, H., Park, J. and Park, K. (2017) Cytotoxicity of nanoparticles in cultured THP-1 cells under the standardized condition of size distribution. Yakhak Hoeji, 61, 109-116.

23. Lee, H., Park, J. and Park, K. (2017) Size distribution of silica dioxide nanoparticles after calibrated sonication and cytotoxicity in cultured A549 cells. Yakhak Hoeji, 61, 309316.

24. Ripps, H. and Chappell, R.L. (2014) Review: zinc's functional significance in the vertebrate retina. Mol. Vis., 20, 1067-1074.

25. Ugarte, M., Osborne, N.N., Brown, L.A. and Bishop, P.N. (2013) Iron, zinc, and copper in retinal physiology and disease. Surv. Ophthalmol., 58, 585-609. 